\title{
Apresentação
}

\section{Língua: cognição e usos}

O volume 46 da Gragoatá reúne 14 artigos dedicados à abrangente temática "Língua: cognição e usos" - além de uma resenha acerca do lançamento de um recém-lançado livro didático relevante na área de ensino de semântica em cursos de graduação e de pós. Trata-se, portanto, de um número em que recentes pesquisas da chamada "linguística da língua", isto é, estudos dedicados ao sistema estruturante das línguas naturais (da fonologia à semântica, da sintaxe à pragmática, da morfologia ao léxico) revelam parte da profícua diversidade de abordagens teóricas e de métodos investigativos empregados em teoria e análise linguísticas neste avançar do século XXI.

Os cinco primeiros textos deste volume tratam da dimensão cognitiva do fenômeno linguístico. Especificamente, os quatro primeiros são obra de psicolinguistas brasileiros. $\mathrm{O}$ artigo intitulado Semantic priming effects and lexical access in English as L3, de autoria de Pâmela Pereira Toassi e Mailce Borges Mota abre essa sequência de textos. Nele, as autoras descrevem e discutem um experimento psicolinguístico de nomeação de figuras com priming encoberto, aplicado com dois grupos de participantes: falantes bilíngues (L1 português e L2 inglês) e falantes trilíngues (L1 português, L2 inglês e L3 alemão) - além de um grupo controle formado por nativos monolíngues do inglês. Os resultados encontrados pelas autoras demonstraram efeito da variável grupal nas reações dos participantes da tarefa aos diferentes tipos de condição experimental, fato que lhes autorizou a interpretação de que o desempenho de falantes em sua terceira língua é afetado pelo conhecimento de sua segunda língua. Tais achados indicam que não somente os recursos cognitivos de acesso lexical são distintos entre falantes monolíngues e bilíngues, como também bilíngues e trilíngues possuem diferentes expedientes mentais para acessar o seu léxico mental.

O segundo texto deste número se intitula Controle metodológico: criação de um corpus para estudos sobre o processamento 
lexical de indivíduos bilíngues e multilingues, de autoria de Nalim Barbosa Pinto e Ana Beatriz Fontes. Assim como ocorre no anterior, as autoras deste artigo também se dedicam ao estudo do processamento lexical de indivíduos que dominam três línguas, uma materna e duas adicionais. Entretanto, Pinto e Fontes argumentam em favor da necessidade de um controle prévio sobre os itens lexicais que venham a compor os materiais de tarefas experimentais de decisão lexical ou de nomeação de figuras. Tal controle, conforme argumentam, perpassa pela identificação da frequência de ocorrência de um item em particular, pela consideração da possibilidade de homonímia de uma determinada palavra e pela observação da eventual existência de cognatos de um item em duas ou mais línguas. A partir desses fundamentos, as autoras descrevem o percurso de elaboração de um corpus trilíngue - português, inglês e italiano - composto por 22 palavras cognatas, 66 palavras não cognatas e 132 pseudopalavras, conjunto de 220 itens que apresentam o equilíbrio desejado para a utilização numa pesquisa sobre acesso lexical com falantes das três línguas.

O processamento de nominais nus em PB: investigando interfaces entre domínios cognitivos, texto assinado por Michele Monteiro de Souza e Cristina Name é o terceiro artigo deste número da Gragoatá. Trata-se de um estudo psicolinguístico de natureza experimental sobre os nomes-nus (bare nouns) no português do Brasil (PB), língua em que o comportamento desses tipos de nome parece ser muito menos restrito do que noutras línguas em que o fenômeno já foi estudado. As autoras lançaram mão de um experimento de nomeação de imagem cujo objetivo foi verificar a taxa de produção de nomes-nus com de certas características semânticas (genérico, tipológico e episódico) em posição pré-verbal, por oposição a Determiner Phrases (DPs) plurais. Os resultados da pesquisa apontam que monolíngues do $\mathrm{PB}$ parecem tratar os nomes-nus como uma construção opcional, achado que fez com que as autoras recorressem à Teoria das Interfaces (SORACE \& FILIACI, 2006) como explicação para os seus dados.

Em seguida, a professora Leonor Scliar-Cabral, no artigo nomeado Modelos psicolinguísticos de produção da linguagem verbal oral, mantém a temática geral dos textos anteriores (o processamento cognitivo da linguagem), porém o faz com um enfoque distinto ao privilegiar a reflexão epistemológica 
sobre o fazer contemporâneo da psicolinguística, aqui posto sob a perspectiva de sua história nas últimas décadas. A autora descreve o cenário da evolução da psicolinguística e aponta possíveis (e plausíveis) razões para a assimetria entre os estudos de produção e de compreensão da linguagem, estando estes últimos muito mais refinados e mais desenvolvidos do que aqueles. Scliar-Cabral aponta as razões metodológicas e ontológicas para tal assimetria e descreve como poderá ser um cenário futuro-próximo em que a distância entre ambas as áreas de pesquisa possa começar a ser diminuída.

O quinto artigo dessa sequência é também dedicado à dimensão cognitiva da linguagem, mas se distingue dos anteriores por assumir uma natureza não simbólica e não computacional para o processamento da linguagem. Trata-se do texto Uma leitura cognitiva do processo de perda não patológica de lingua materna, de Felipe Flores Kupske e Athany Gutierres. Os autores vinculam seu artigo ao paradigma conexionista e se propõem à análise de um fenômeno de fato subexplorado na literatura sobre linguagem e mente/cérebro: o atrito em L1, interpretado como perda não patológica. O artigo elenca diversos exemplos interessantes sobre atrito em L1 e demonstram como a abordagem conexionista pode explicar tais casos, em cotejo com a situação típica de uma língua natural.

O sexto artigo deste número interrompe a sequência orientada pela psicolinguística dos anteriores e apresenta uma abordagem mais abstrata, caraterística do tratamento formal dos estudos em teoria da gramática. Trata-se de Observações sobre o pejorativo sufixal: testando a intuição dos falantes diante de uma teoria de fase nas palavras, escrito por Rafael Dias Minussi e Caroline da Silva Oliveira. Trata-se de uma análise baseada na morfologia distribuída (HALLE; MARANTZ, 1993; MARANTZ, 1997) que busca investigar fenômenos da interface sintaxe-semântica na formação de nomes com valor pejorativo em $\mathrm{PB}$, considerando-se as bases lexicais, os afixos e os respectivos produtos derivacionais. Os autores investigaram a intuição dos falantes brasileiros acerca de 306 itens lexicais extraídos de diversos gêneros textuais orais e escritos e chegaram à formulação de uma "escala de pejoratividade", a qual se descreve, no artigo, no âmbito da teoria de fase nas palavras (MARANTZ, 2001; ARAD, 2003) 
Na sequência deste número, apresentamos seis textos representativos da autointitulada linguística baseada no uso. Começamos com o nosso sétimo artigo, escrito pela profa. Erotilde Goreti Pezatti e intitulado Miniorações em anúncios sob a perspectiva discursivo-funcional. $\mathrm{O}$ texto apresenta uma análise de frases nominais em PB extraídas de textos do século XIX e XX. As frases em questão representam um tipo de manifestação da díade tópico > foco que, segundo a autora, revela "uma estratégia de adaptação aos objetivos comunicativos do usuário na interação, tanto em termos de formulação pragmática e semântica, quanto em termos de codificação morfossintática e fonológica".

Sávio de Souza Cavalcante e Violeta Virgínia Rodrigues são os autores de $A$ estrutura argumental preferida de cláusulas hipotáticas circunstanciais temporais desgarradas em memes 'quando', o oitavo artigo deste volume. Os autores analisaram 100 orações em memes encontrados em pesquisas no Google e no Instagram a fim de verificar as hipóteses da Estrutura Argumental Preferida - EAP (DU BOIS, 1987). Os dados da pesquisa revelaram forte preferência para a ordenação $\mathrm{SV}(\mathrm{O})$ com verbos de ação - e, menos fortemente, com verbos de estado - flexionados no presente do indicativo. Para os autores, esses dados confirmam parcialmente as previsões da EAP, uma vez que sujeitos de verbos biargumentais são tipicamente pronominais, pré-verbais e velhos, enquanto objetos de verbos biargumentais são itens lexicais plenos, pós-verbais e novos por sua vez, verbos monoargumentais existenciais são lexicais/ pronominais, pré-verbais e novos/velhos, por contraste aos monoargumentais não existenciais que, tipicamente, são lexicais/pronominais, pré-verbais e novos.

$\mathrm{O}$ artigo seguinte preserva a temática oracional dos dois anteriores, é assinado por Patrícia Rodrigues e recebe o título de Orações causais e estrutura informacional da sentença. Rodrigues análise o caso das causais introduzidas por "porque" e defende a hipótese de que tais estruturais, para serem analisadas com adequação descritiva, precisam ser consideradas no âmbito da estrutura informacional da sentença. Para a autora, causais desse tipo nem sempre são focalizadas e nem sempre constituem orações subordinadas de predicado. De acordo com sua argumentação, as causais com "porque" podem ser associadas a uma única ou a mais 
de uma estrutura de foco-pressuposição. Assim sendo, tais orações não seriam subordinadas de predicado, mas, antes, seriam subordinadas da sentença.

Vanda Cardozo de Menezes é autora de Quando 'falar' vira ordem: a construção 'falar para Infinitivo' em português, uma explicação cognitiva, o décimo artigo deste número. No texto, faz-se uma oposição entre dados do PB e do português europeu (PE) com relação a estruturas sintáticas com o verbo "pedir" e o verbo "falar" seguidos da preposição "para", à qual se segue um verbo no infinitivo. Menezes procurou identificar "as operações cognitivas envolvidas nos processos de conceptualização que permeiam as escolhas dos falantes, tanto no sentido para a estabilidade quanto para a mudança semântica" (TRAUGOTT, 1989; TRAUGOTT e DASHER, 2002; LANGACKER, 2008). Nesse sentido, por um lado, tanto a opção por um verbo ou outro, bem como, por outro lado, as distinções entre PB e PE devem revelar certas concepções de perspectivação e de subjetificação subjacentes ao uso da língua. A autora concluiu seu artigo defendendo a hipótese segundo a qual a construção "falar para infinitivo" ilustra um caso de mudança semântica no $\mathrm{PB}$, tanto na oralidade quanto na escrita.

O artigo que conclui essa espécie de seção "funcionalista", "baseado no uso" é Polissemia nos usos do verbo ter: arbitrariedade ou iconicidade? Uma questão de ponto de vista, de Cleiliane Sisi Peixoto. O texto ressuscita a dicotomia analogia versus anomalia para discutir aspectos polissêmicos de um item lexical do português considerado diacronicamente. A autora defende a hipótese de que a arbitrariedade dos usos de verbo "ter" no PB contemporâneo mascara os icônicos empregos polissêmicos que esse item encarnava em sincronias anteriores da língua.

$\mathrm{O}$ artigo seguinte apresenta uma abordagem teórica diferente em relação a todos os anteriores. Trata-se de Espacialidade e processos metonímicos na canção Querência amada, de Odair Silva dos Santos e Heloísa de Moraes Feltes, que é o décimo segundo artigo da Gragoatá 46. O texto articula fundamentos da linguística sociocognitiva para proceder a uma análise de expressões metafóricas em Querência Amada, "canção que se tornou hino e ícone de sucesso no âmbito dos movimentos tradicionalistas" da cultura do Rio Grande do Sul. Em especial, a análise empreendia enfatiza o papel da 
metonimização e dos frames históricos e socioculturais e nas referências espaciais tão caras à cultura gaúcha.

Na sequência do presente volume, a próxima dupla de artigos contempla aspectos fonológicos do $\mathrm{PB}$, examinados sob diferentes perspectivas teórico-metodológicas. $\mathrm{O}$ primeiro deles denomina-se $A$ vitalidade identitária de contornos entonacionais característicos do falar manezinho, cujos autores são Izabel Christine Seara, Juan Manuel Sosa e Roberta Pires de Oliveira. "Manezinho" é uma variedade dialetal não urbana do português falado na Ilha de Santa Catarina. Os autores realizaram uma análise do contorno entoacional que particulariza essa variedade específica do PB. Em sua análise de interface entre fonologia e semântica/pragmática, os Seara, Sosa e Pires de Oliveira assumem que os dados apresentados no artigo indicam que falantes manezinhos e não manezinhos atribuem diferentes interpretações (declaração x interrogação) a um mesmo enunciado proferido por um falante manezinho. O segundo artigo de nossa dupla fonológica é Saliência na conservação de /d/ no segmento /ndo/: efeitos sociais e estilísticos, de Raquel Meister Freitag, Paloma Batista Cardoso e Bruno Marques Pinheiro. No texto, analisam-se a saliência fônica e a consciência social envolvidos na conservação de segmento /d/ no gerundivo /ndo/ com dados de fala de Aracaju. Segundos os autores, o /d/ se preserva mais tipicamente na fala de mulheres, com ensino superior e em prosas sobre temas de maior formalidade, servindo como uma espécie de marcador sociolinguístico.

Por fim, o número 46 de nossa revista apresenta a seus leitores a resenha do livro Para conhecer: semântica, lançado recentemente pela Editora Contexto (São Paulo) e escrito por Ana Quadros Gomes (professora da UFRJ) e Luciana Sanchez Mendes (professora da UFF). A resenhista é Fernanda Rosa Silva, estagiaria de pós-doutoramento no GEPEX (Grupo de Estudos e Pesquisas em Linguística Teórica e Experimental, da UFF). Silva descreve os capítulos da obra e demonstra como essa vem a preencher uma lacuna na biblioteca de formação básica de alunos de letras e de linguística brasileiros.

Acreditamos que os artigos aqui publicados manterão a tradição das publicações anteriores da Gragoatá. Isto é, esperamos que eles possam provocar reflexões, críticas e 
diálogos que façam avançar o conhecimento sobre as línguas naturais, seja em sua dimensão cognitiva abstrata ou em suas contingências específicas de usos concretos.

Boa leitura!

Eduardo Kenedy

Universidade Federal Fluminense

Marta Donazzan

Université de Nantes

ORGANIZADORES 